\title{
¿TE CUENTO UNA HISTORIA DE HORROR? REPRESENTACIÓN DE LA MATERNIDAD EN LA OBRA RECIENTE DE MARIANA ENRIQUEZ Y DE SAMANTA SCHWEBLIN*
}

\section{DO YOU WANT TO HEAR A HORROR STORY? REPRESENTATION OF MOTHERHOOD IN THE RECENT WORKS OF MARIANA ENRIQUEZ AND SAMANTA SCHWEBLIN}

\section{CATALINA FORTTES ZALAQUETT ${ }^{\star *}$}

Resumen: El objetivo de este artículo es analizar la representación de la maternidad en una selección de cuentos de Mariana Enriquez y de Samanta Schweblin, que se lee a partir de las convenciones del género gótico. Argumento que el uso de este género permite problematizar la representación de la maternidad y las labores de cuidado por medio del horror, y así llamar la atención sobre las ansiedades que en nuestra cultura suelen justificar la intervención patriarcal. Este trabajo se centra en dos convenciones representativas del género: primero, la casa acechada como un espacio en el cual se representan los horrores individuales y sociales que los mandatos maternales de una cultura patriarcal reprimen o encubren; y, segundo, la intervención tecnológica como forma de dominio y/o eliminación de la madre de los procesos reproductivos. El análisis de los cuentos a partir de estos motivos permite la exploración del horror asociado a la experiencia de maternar en contextos patriarcales, aspecto cuya representación excede las posibilidades representativas del realismo.

Palabras clave: Mariana Enriquez, Samanta Schweblin, narrativa gótica, maternidades, cultura patriarcal.

Aвstract: The objective of this article is to analyze the representation of motherhood in a selection of short stories by Mariana Enriquez and Samanta Schweblin as read within the conventions of the gothic genre. I argue that the use of the genre enables the problematization of the representation of motherhood and care work as horror draws attention to the anxieties that, in our culture, have justified patriarchal intervention. This analysis focuses on two conventions featured by the genre: first the haunted house as the space where maternal mandates repress individual and social horrors; and secondly, technological intervention as a way to dominate and/or eliminate the mother

\footnotetext{
* Artículo asociado al proyecto Fondecyt Regular No 1200535, "Narrar lo indecible: Gótico, autoficción y maternidad en la narrativa latinoamericana reciente".

** PhD. en Lenguas y Literaturas Hispánicas. Académica de la Pontificia Universidad Católica de Valparaíso, Valparaíso, Chile. Correo electrónico: catalina.forttes@pucv.cl. Orcid: https://orcid. org/0000-0002-7072-1474
} 
from reproductive processes. The analysis of these motives within the stories allow the exploration of the horrors associated to mothering within patriarchal contexts, that escape the representative possibilities of realism.

KeYwords: Mariana Enriquez, Samanta Schweblin, gothic narrative, motherhoods. patriarchal culture.

Recibido: 11.03.2020. Aprobado: 12.01.2021.

Cegún Eve Kosofsky (1980, p. 9), hay pocos géneros tan fieles a sus $\checkmark$ convenciones como el gótico, y estas se pueden reconocer incluso desde el título. El gótico es un género de más de doscientos años que se inaugura en 1764 con la publicación de El Castillo de Otranto de Horace Walpole ([1764]2016), y con esta novela sobre un castillo acechado por espíritus malignos se da inicio a una poderosa tradición que ha contribuido a la exploración, tanto en la literatura como posteriormente en el cine, de la parte de la experiencia humana que se esconde de la luz. Los imaginarios del gótico se nutren de castillos o casas acechadas, espacios decaídos, paisajes salvajes, sociedades jerárquicas y supersticiosas, heroínas encerradas, amantes impulsivos, figuras paternas tiránicas, huérfanos y madres ausentes o locas; y se movilizan a partir del uso de temporalidades transicionales, intriga, manipulación y miedo.

Algunas de estas convenciones han migrado hacia otros géneros, sin embargo, siguiendo a Kosofsky (1980), lo que siempre lo define es su disposición a representar lo indecible, aquella dimensión escindida de la experiencia que se escenifica en el gótico mediante la recurrencia del motivo del "entierro vivo" (pp. 14-15), es decir, el confinamiento literal o metafórico de aquellos aspectos de la vida que escapan a la norma o bien aquellos que obstaculizan la expresión de la hegemonía.

Este artículo lee la representación de la maternidad en los cuentos "El chico sucio", "El patio del vecino", y "Verde rojo anaranjado" de Las cosas que perdimos en el fuego de Mariana Enriquez (2016), y "Conservas", "En la estepa" de Pájaros en la boca y "Nada de esto" de Siete casas vacías de Samanta Schweblin (2015b y 2015a, respectivamente), como relatos en los que se "entierra viva" la figura de la madre. Argumento que en estos textosse representan simbólicamente las ansiedades asociadas a la maternidad que llaman a la intervención patriarcal por medio de dos convenciones características del género. Estas son, primero, la casa acechada que encierra a una mujer cuidadora y, segundo, el control o reemplazo de la mujer en los procesos reproductivos mediante la intervención tecnológica. Interesa 
también en esta discusión identificar la operación hegemónica que en los cuentos transforma todo aquello que no comprende o domina en algo espeluznante. El horror funciona consecuentemente como frontera visible de los límites de la capacidad de razón (ilustrada) y el realismo (su lenguaje) para representar las complejidades de la maternidad. Así, el realismo sería cómplice de la cultura patriarcal y burguesa, en tanto que el gótico desafiaría las restricciones expresivas que delimitan la experiencia maternal. En este sentido, el horror tiene por función hacer visibles las formas de violencia que se ejercen sobre la reproducción y el cuidado de la vida.

El horror también se ha utilizado en el cine a partir de los años setenta para representar la crisis de las expectativas en torno a la maternidad en películas como: Rosemary's Baby (Polanski,1968), The Others (Amenábar, 2001), The Babadook (Kent, 2014) y Mother! (Aronofsky, 2017). Estas películas repiten las convenciones de la casa acechada para prefigurar a madres que fallan. La madre que, en lugar de dar vida, invoca a la muerte, o en lugar de formar, deforma, llama a la intervención patriarcal para así proteger la vulnerabilidad infantil y perpetuar la subordinación maternal. Esta intervención también se representa en el cine de ciencia ficción de inspiración gótica mediante la creación de un mundo en el cual la razón técnica ha encontrado formas de conquistar la reproducción de la especie, sin la madre. No obstante, y a diferencia del cine, los cuentos de Schweblin y Enriquez elaboran las posibilidades del gótico literario de no solo evidenciar la ansiedad frente al deslizamiento de las categorías maternales hacia nuevos espacios y formas, sino que también de dar cuenta de la insuficiencia de estas categorías.

Jeffrey Cohen (1996) establece que las culturas pueden leerse a partir de sus monstruos y que los relatos de horror dramatizan las ansiedades y miedos individuales y sociales que los discursos legitimados no apaciguan. De esta manera, la actualización del género gótico posibilita, en la narrativa de las escritoras mencionadas, la expresión de intensidades que exceden el confinamiento discursivo de la razón patriarcal y la materialización simbólica de la ansiedad que genera la complejidad y el impacto social del ejercicio de la maternidad.

Flannery O'Connor (1970 p. 40), quien ocupa un lugar privilegiado dentro de la tradición gótica del siglo XX, planteó que todo lo que salía del sur (de Estados Unidos) era grotesco para el norteño, cuando para el sureño era la vida misma. De la misma forma, en nuestro sur, lo grotesco y el gótico dan cuenta de los ajustes, escisiones y oscurecimientos implicados en los procesos de modernización burguesa de las distintas geografías 
culturales latinoamericanas. El poeta y cronista nicaragüense Rubén Darío (1896) inaugura, con "Los raros", la exploración latinoamericana de una sensibilidad concadenada a la subjetividad y a los marcos expresivos del gótico y el simbolismo. Desde Edgar Allan Poe a Rachilde (Marguerite Vallette-Eymery) y a José Martí, Darío hace la semblanza de un artista "raro" que en su escritura desafía la mirada realista para poner el foco en lo latente, lo impredecible y lo indomable que subyace a la representación simbólica. Podríamos decir que Darío es el primero en teñir el gótico de los colores locales al trabajarlo como forma de comentar los excesos de la cultura burguesa, las transformaciones en los roles de género y, en la línea de este análisis, también actualiza la figura de la madre monstruosa en cuentos como "Thanatopía" ([1925] 1995). Los estados de semi-conciencia, las drogas, el fetichismo demoníaco, las mujeres vampiras, enfermas o muertas, funcionan no solo en Darío como tropos modernistas, sino también en autores como el guatemalteco Vargas Vila o el peruano Clemente Palma, quienes encuentran en el gótico y en especial en E.A. Poe un imaginario para hablar de su condición poscolonial y el desafío tanto conceptual como material de representar los espacios geográficos extremos de Latinoamérica ${ }^{1}$. Más al sur del continente, tanto Leopoldo Lugones (1906) en Las fuerzas extrañas como Horacio Quiroga ([1910] 1994) en El hombre artificial revisan mediante el uso del horror y la ciencia ficción los límites del saber positivista, a la vez que resaltan la bestialidad latente bajo las formas burguesas. Estos son temas que, como se revisará más adelante, los cuentos de Mariana Enriquez y de Samanta Schweblin ponen en relación con el deseo, el miedo y el control de la maternidad.

Julio Cortázar (1975) plantea que el "polimorfismo cultural, derivado de los múltiples aportes migratorios", además de "nuestra inmensidad geográfica como factor de aislamiento" (p. 146) son elementos que contribuyen a la construcción de una mirada gótica rioplatense que se manifiesta en autores como Jorge Luis Borges, Adolfo Bioy Casares, Felisberto Hernández y Silvina Ocampo. El gótico posibilita la transgresión de los límites representativos del realismo y permite, según Cortázar, instalarse "en el terreno de lo otro" (p. 148). Una de las formas en que Cortázar y Ocampo articulan una visión gótica del mundo es mediante la inclusión de una subjetividad infantil en la representación de espacios cotidianos y domésticos que pierden su carácter familiar para transformarse en acechantes. Cortázar (1956)

\footnotetext{
${ }^{1}$ Existen manifestaciones del gótico en Latinoamérica anteriores al modernismo, como en el caso excepcional de la argentina Juana Manuela Gorriti, quien en 1865 publica la colección de cuentos Sueños y realidades.
} 
en cuentos como "Los venenos" o "Final del juego" y en "Cielo de claraboyas" ([1937] 1999) o "El vestido de terciopelo" ([1959] 2006) hacen que los niños reflejen la crueldad y el narcisismo de los adultos y la casa (especialmente aquella donde las madres están ausentes) se represente como un espacio donde lo inanimado puede sorpresivamente cobrar vida².

La casa gótica está también en el centro de la narrativa de José Donoso y María Luisa Bombal. Tanto Donoso en Coronación (1957) y El obsceno pájaro de la noche (1970), como Bombal en La última niebla (1931) y La historia de María Griselda (1946) construyen sus relatos en torno a sujetos encerrados en casas y marcos sociales represivos, y por sobre todo estériles. En estos textos, la vida que no se puede reproducir deviene monstruosa. La casa que el psicoanálisis lee como proyección del útero es el espacio de lo abyecto, pues como conceptualiza Julia Kristeva (1988), a partir de su análisis de la etapa del espejo de Lacan, hace referencia a la vulnerabilidad extrema del momento pre-semiótico en que, como infantes, estuvimos conectados con el cuerpo materno y, por extensión, también con el espacio del hogar.

\section{LO SINIESTRO DE TODOS LOS DÍAS: LA CASA COMO "MAL LUGAR"}

En los cuentos "El chico sucio" y "El patio del vecino" de Mariana Enriquez y "Nada de esto" de Samanta Schweblin, la casa funciona como sustento de las construcciones patriarcales de la cultura burguesa dentro del contexto de la Argentina neoliberal del cambio de siglo. Analizo aquí la representación de la casa y el hogar como funcional a la demonización de la madre (figura que gobierna este espacio), transformación que justifica la intervención patriarcal.

Sigmund Freud ([1919] 2003, pp. 124-25) ancla su concepto de "lo ominoso" en el espacio doméstico, pues unheimlich significa literalmente en alemán, "la negación del hogar (Heimlich)", palabra que se asocia con lo íntimo, lo secreto, lo familiar y lo acogedor. El hogar es el espacio conocido, donde desde infantes construimos los apegos, por lo que una distorsión de lo familiar interfiere a nivel primario con la forma en que se lee la realidad. Lo "ominoso" sería una alteración o irrupción en el espacio y el tiempo del hogar y la incertidumbre intelectual que se genera en el momento en que

\footnotetext{
${ }^{2}$ Para una revisión exhaustiva de la expresión del gótico en las literaturas de Argentina, Chile y Uruguay, revisar Ecos góticos en la novela del Cono Sur de Nadina Olmedo (2013).
} 
se desfamiliariza lo familiar. El pavor que produce lo unheimlich se sitúa en la lectura de Mary Tatar (1981) precisamente en que es simultáneamente extraño y familiar (p. 169). La ambigüedad que surge de la cualidad sobrenatural de lo extraño en relación a las explicaciones realistas de lo familiar, sería la tensión que para Tatar define lo ominoso y de la cual se nutren los géneros fantásticos:

Lo fantástico obtiene su vitalidad en un evento que al desafiar la razón rompe con la estabilidad del mundo y produce una pérdida radical de arraigo. El mundo antes seguro, se convierte en hostil y traicionero. Este nuevo mundo se sitúa en la encrucijada entre lo heimlich y lo unheimlich, en el punto exacto en que las dos palabras convergen para sugerir lo siniestro y lo opresivo. (p. 182, trad. propia).

Lo ominoso no emerge según Freud de lo nuevo, ni extraño, sino de lo familiar que ha sido distanciado producto de un proceso represivo (p. 148). Las casas son el escenario para la aparición de lo oscurecido, lo primitivo -aquello que se dejó en la infancia o en un tiempo anterior de la línea familiar- , o bien aquello que se disocia de la vida psíquica, pero que de igual manera la acompaña. Es a partir de la inestabilidad o la ambigüedad de lo ominoso que podemos proyectar las casas acechadas representadas en las obras como lugares donde las nociones de tiempo y espacio colapsan para hacer del hogar un espacio desfamiliarizado, y este es el tipo de hogar en el cual reside una madre que falla.

Para Stephen King (1987, p. 159), el principal referente contemporáneo al momento de representar casas abandonadas que despiertan curiosidad infantil, la casa acechada se relaciona con uno de los cuatro arquetipos en los cuales se basa la literatura gótica: el vampiro, el hombre lobo, "la cosa sin nombre" y el fantasma. El fantasma está vinculado al espacio material de la casa y es mediante el asedio y la aparente animación de lo inerte que hace colapsar el presente con el pasado y la vida con la muerte. King denomina este lugar como el "bad place" ("mal lugar") y lo define como un lugar que cuenta con una historia desagradable. Es más, un buen relato de horror nos obliga a encontrarnos con esa historia al encerrarnos en y con ella (1987, p. 160).

Dani Cavallaro (2002, p. 86) establece que en la tradición gótica la arquitectura acechada por lo sobrenatural funciona como antítesis de aquello que desde la Ilustración en adelante se considera como civilizado. El adjetivo "gótico" se ancla en una asociación con el oscurantismo medieval, lo bárbaro, los espacios no controlados o no utilizados de forma racional, 
donde se difuminan las distinciones de adentro y afuera, o lo artificial y lo natural. El espacio calificado como gótico es anterior a los códigos burgueses, o bien un lugar donde estos se suspenden ${ }^{3}$. Cavallaro (2002, p. 86) apunta a las posibilidades disruptivas y políticas inherentes a la representación de construcciones acechadas, ya que materializan el daño y la oscuridad de las estructuras de poder que nos gobiernan.

King (1987, p.168), al caracterizar la ficción gótica americana contemporánea, establece que la casa ha dejado de funcionar simbólicamente como útero y que se ha transformado en espejo. De este modo, la casa acechada funciona como manifestación material de una obsesión por el estatus. La madre siempre sonriente y abocada a conseguir la perfección de sus hijos y del espacio doméstico se representa así en esta ficción como una figura que cuaja las ansiedades aspiracionales y el narcisismo suburbano de la generación que hace familia en la posguerra. Esta madre perfecta puede mutar rápidamente y transformarse en un ser amoral capaz de producir o invocar el horror para conservar su estatus económico y social. La posibilidad de transformación inesperada de la dueña de casa ya había sido conceptualizada en los años sesenta por las críticas feministas Sandra Gilbert y Susan Gubar (1979) a partir el binomio ángel-monstruo, sin embargo, estas sitúan el origen de esta representación híbrida e inestable de la mujer en una narrativa decimonónica que canaliza los miedos asociados a la omnipresencia femenina en el espacio doméstico.

Samanta Schweblin actualiza la figura de la madre que se transforma inesperadamente en el cuento "Nada de esto" que abre Siete casas vacías. Movida por el deseo incontrolable de habitar una casa burguesa como las que ha visto en revistas de decoración, una madre, que producto de la viudez ya no encuentra freno a la puesta en acción de sus obsesiones, involucra a su hija adulta en una invasión pseudo criminal de una casa pudiente. El cuento se inscribe en una tradición de cuentos de horror que escenifican el miedo de la burguesía a la invasión popular de sus espacios, como "Casa tomada" de Julio Cortázar (1946) o "Los caballos de Abdera" de Leopoldo Lugones (1906), y la renueva por medio de una representación siniestra de la subjetividad invasora. La narradora desde pequeña acompaña a su madre a barrios acomodados a mirar casas de gente rica e intervenir dis-

\footnotetext{
${ }^{3}$ La casa acechada por lo sobrenatural no necesariamente es un castillo en ruinas de la Europa considerada exótica en el imaginario victoriano, sino que, y especialmente en las representaciones americanas del gótico, la casa acechada tiende a ser una casa burguesa o suburbana, acechada por fantasmas que tienen por función revindicar pasados obliterados, ajusticiar agravios o revelar los costos de mantener las estructuras ideológicas que representan.
} 
cretamente los espacios, pues juntas mueven maceteros o cortan flores sin ser vistas. Lo que horroriza en la historia, además de la transformación que sufre la madre cuando entra en contacto con su objeto de deseo, es también la forma en que el delirio maternal aprisiona a una hija ya adulta.

Los moradores de la casa (una dueña de casa con su hijo pequeño) no están preparados para enfrentar a una mujer que finge un paro cardíaco para invadir su espacio y experimentar, aunque sea de forma pasajera, el mármol, las alfombras de lana y la grifería de una casa igual a las de las revistas de decoración. La madre, poseída por la experiencia material, va transgrediendo los espacios privados de la familia burguesa hasta llegar a la alcoba con baño de la dueña de casa, quien se paraliza ante la impredictibilidad de los acontecimientos. Solo la amenaza de intervención del marido que viene en camino y una ambulancia logran romper el trance de goce material de la madre y convencerla de escapar. Sin embargo, las transgresiones de la madre continúan, pues se ha llevado un azucarero de la casa burguesa, un souvenir que de alguna forma contiene la experiencia de la visita. El objeto se vuelve siniestro y poderoso al trasladarse a la casa de clase media empobrecida, y no tarda en atraer a la dueña de casa burguesa, quien toca el timbre para recobrarlo. El azucarero perteneció a su madre muerta y como es el único objeto de su casa no asociado a la afirmación de su estatus, sino de un afecto y una memoria, le implora que se lo devuelva. La materialidad acechada del azucarero expone nuevamente a las mujeres a un encuentro que, esta vez, empuja a la mujer burguesa a conocer los espacios de los que viven acechados por la aspiración a los privilegios de los que ella goza. La casa funciona, así, como espejo de una pasión doméstica que reduce la experiencia maternal a una materialidad que en lugar de posibilitar el cuidado, escenifica las obsesiones maternas.

"El chico sucio", cuento que abre Las cosas que perdimos en el fuego, de Mariana Enriquez también ubica el horror en la irrupción de una realidad social carente en un espacio doméstico acomodado. Como primera imagen del cuento, se levanta una antigua casa heredada en el barrio de Constitución, al sur de Buenos Aires, una casa cuya arquitectura burguesa funciona como anacronismo fantasmal en un barrio empobrecido. El que nunca haya podido retener a sus moradores puede ser leído como señal de una latencia que acecha desde que en las postrimerías del siglo XIX, la aristocracia que la habitaba huyó de la peste bubónica hacia el norte de la ciudad. Quedaron sus caserones con gárgolas a disposición de clases sociales emergentes, pero, el barrio -como dice la narradora- : "quedó marcado por la huida, el abandono, la condición de indeseado" (p. 10). Sin embargo, 
a la narradora le gusta la casa y su contexto, pues esta escenifica a diario su anacronía y, además, el tránsito por espacios difíciles y peligrosos la hace sentir "precisa y audaz, despierta (p. 11). En el barrio vive mucha gente en condición de calle y en un galpón frente a la casa habitada por la protagonista y narradora, vive una joven madre adicta y embarazada con un hijo de aproximadamente cinco años. El niño pide limosnas en el transporte público y una noche de mucho calor toca el timbre de la casa de la narradora. El niño dice que lo han dejado solo "con la cabeza", y la narradora lo acoge y alimenta para luego caminar juntos a comprar un helado por calles tenuemente iluminadas por las velitas de los altares al "Gaucho Gil" de un lado de la estación y "San la muerte”, del otro. Coherente con la convención gótica, al contexto lo determina tanto la superstición como la existencia de una estructura violenta que en este caso se manifiesta en el desamparo infantil. A pesar de esto, la narradora se mantiene indiferente a las prefiguraciones del horror y se enfoca en lo pragmático: ¿Qué hacer con el niño si no aparece su madre?, ¿qué se hace con niños como él? La narradora reflexiona: "Me daba cuenta... de lo poco que me importaba la gente, de lo naturales que me resultaban esas vidas desdichadas" (p. 19), aludiendo a vidas que, como establece Judith Butler (2009), "no lamentamos", y que en los cuentos de Enriquez se convierten en fantasmas.

Al día siguiente, la madre y el niño han desaparecido; a la semana aparecen los restos de un niño degollado y su cabeza colocada al lado de su cuerpo torturado; y a los días, la narradora se encuentra de regreso a casa con la madre adicta y la aborda con agresividad para preguntarle por el niño. La mujer le dice que no tiene hijos, logra escapar y luego le grita, "se los di", y, sobándose la panza, le vuelve a gritar: "este también se lo di" (p. 32). La narradora vuelve a su casa, pero la casa ha dejado ser el refugio romántico de una burguesa con espíritu de aventura. Quizá ya "no era la princesa en el castillo, sino la loca encerrada en la torre" (p. 32), una mujer sola en una casa que es invadida por fantasmas. El niño como un vampiro tocó la puerta, y al dejarlo entrar, la mujer dejó entrar a los que nunca vio, porque no quería. El horror, los miedos y los fantasmas que habitan los barrios de los desposeídos se manifestaron, son sociales y acecharán hasta

\footnotetext{
${ }^{4}$ Para Judith Butler el que seamos capaces de lamentar la pérdida de una vida es la condición que posibilita la consideración del ser vivo como efectivamente vivo (p. 15). En esta línea, la narrativa de Enríquez ilumina un ámbito de la realidad citadina contemporánea que las sensibilidades más acomodadas se esfuerzan por no ver, pues tanto psicológica como logísticamente se hace difícil o incómodo tomar conciencia de las formas en que la vida es amenazada por la miseria y la marginalidad.
} 
expulsar a las sensibilidades burguesas que, como turistas, pueden jugar con la idea de reivindicar un barrio, o cuidar a un niño por una noche.

Una mujer sin hijos en una casa ominosa, que siente el llamado a proteger a un niño, también es el centro del cuento "El patio del vecino". Paula, la protagonista, es una ex asistente social acechada por los fantasmas que conoció en su antiguo trabajo. Paula se presenta como una especie de "madre social" que se dedica al cuidado de niños de la calle hasta que comete un error y la despiden. Como parte de su proceso de superación de la depresión que sigue al despido, Paula y su marido Miguel llegan a vivir a una casa de clase media que misteriosamente le arriendan a un precio que pueden pagar, prefigurándose que lo que parece un nuevo comienzo, será escenario para el horror. Los ruidos extraños que únicamente oye Paula y las noches acechadas por la visión de un niño monstruoso no tardan en aparecer. Un día colgando ropa divisa en el patio de al lado un niño pequeño, inmundo y con una cadena atada al tobillo. Paula maneja los protocolos de acción para dar cuenta de este tipo de vulneraciones, sin embargo, todavía está fresco el recuerdo del despido de la casa de tránsito en la que trabajó. El sumario dictó que una pequeña se quebró el tobillo al caer de su litera mientras Paula y un colega fumaban mariguana en la cocina al ritmo de una cumbia (a todo volumen según los vecinos). El horror que define la vida de los niños de la calle no respeta el cansancio de la asistente social, devenida madre social y tanto ella como su colega no estuvieron a la altura al enrostrarle a los niños su soledad. Por eso cuando Paula le comunica a su marido su descubrimiento, este -siguiendo la convención gótica- pone en duda su salud mental y asume que lo que su esposa vio en el patio del vecino es un síntoma de su depresión. A pesar de esto, y en la línea de las heroínas decimonónicas, Paula decide entrar en la casa y enfrentar los monstruos sabiendo que fracasará, pues, le consta que los niños traumados a ese nivel nunca se recuperan. La casa vecina escenifica una especie de delirio abyecto. Hay carne podrida en la alacena y las paredes están completamente cubiertas de una escritura diminuta. Paula no ve al niño y cuando escucha las llaves de la puerta huye hacia su casa por el patio de atrás. Pero, cuando cree que está a salvo se encuentra con el niño y su gata en brazos. El niño devora a la gata y la próxima en ser comida por el niño es Paula, quien cierra el cuento con la certeza de que no está soñando. Paula es literal y figuradamente devorada por sus fantasmas, "enterrada viva" en su propia casa por los niños que no supo cuidar y sobre todo por una realidad más grande que los protocolos de acción que manejaba. El niño monstruoso que acosa los cuentos de Enriquez no puede ser exorcizado ni redimido desde la maternidad social o 
biológica individual, ya que encarna realidades impensables para la sensibilidad burguesa de las protagonistas de sus cuentos. La mujer que siente el llamado a cuidar al niño desamparado invita a su casa el horror, pues, ni su valentía, progresismo o vocación puede mitigar el daño del abandono de un infante en un mundo determinado por fuerzas oscuras que se alimentan de la vida nueva.

\section{LA RAZÓN TÉCNICA Y LA DESAPARICIÓN DE LA MADRE}

Mary Shelley (2013) tempranamente advierte que la exclusión de la figura arquetípicamente encargada de la protección de la vida y sus soportes caracteriza los nuevos procesos industrializados de producción. El monstruo creado por Víctor Frankenstein nace de la arrogancia, la fe en la ciencia y la omisión de la madre en la reproducción y el cuidado de la vida. El científico abandona su creación a su suerte y la lengua que aprenderá el monstruo será la de la violencia representada en los textos de nuestra cultura, y no la del cobijo maternal.

En esta sección actualizo el tema de la ausencia materna, ampliamente trabajado en el gótico decimonónico, en los cuentos "Conservas" y "En la estepa" de Samanta Schweblin, pues estos grafican la intervención de la ciencia en la concepción, tanto para revertir como para perseguir una maternidad que en los relatos deviene monstruosa. Leo también el cuento "Verde rojo anaranjado" de Mariana Enriquez, como representación de la intervención tecnológica en el vinculo filial y las ansiedades que esta fusión genera.

Postulo aquí que la razón técnica, entendida como la instrumentalización de la racionalidad ilustrada y su reducción a un ejercicio de dominio, reemplaza, excluye o pervierte las funciones de la madre. La ausencia materna es una de las sombras mediante las cuales el gótico decimonónico representa la adaptación de la experiencia a los procesos de industrialización y la implementación de una nueva relación de dominio extractivista con el cuerpo humano y las ecologías culturales y naturales que lo sostienen ${ }^{5}$. David Punter (1999) establece que el género gótico funciona como un parásito (p. 3) dentro de las formas culturales imperantes debido a que las pervierte

\footnotetext{
${ }^{5}$ Me baso aquí en la elaboración que hacen Max Horkheimer \& Theodor Adorno (2002) en Dilectic of the Enlightenment en torno al concepto de la Ilustración y la forma en que en el mundo occidental la llevó a la práctica mediante el dominio y la explotación del ser humano y la naturaleza (pp. 30-32).
} 
desde adentro. El gótico da cuenta así de los fantasmas que acechan los ejercicios de certeza científica desde el siglo XVIII en adelante, ya que como postula: "la luz del mundo diurno y pragmático sobrevive gracias a que se repliega sobre el mundo espectral del deseo" (p. 3, trad. propia).

La intervención tecnológica en los procesos reproductivos es en la tradición literaria moderna un tropo para la construcción de mundos distópicos en los cuales se complican las fronteras de lo humano y se desafían los lazos de la humanidad con su propia historia y proyección futura (Heise-von der Lippe, 2017, p. 7). La crítica ha clasificado los textos góticos en los cuales el horror surge de la fusión del desarrollo tecnológico y la experiencia humana como "gótico posthumano", y los ha caracterizado mediante la representación de una condición humana acechada por tecnologías de su propia factura. Sin embargo, Michael Sean Bolton (2014) plantea que la contribución de estos textos excede la conceptualización de la tecnología como otredad monstruosa, pues este es un tema que se puede rastrear hasta las obras de maestras decimonónicas como Mary Shelley o Ann Radcliffe. Lo que en la lectura de Bolton es particular al "gótico posthumano" es la forma en que la asimilación de nuevas tecnologías permite una exploración de la subjetividad y los valores que culturalmente asociamos a la condición humana. El horror emerge de la rotura del binomio humano/máquina y la consecuente apropiación de la eficiencia amoral de la máquina, la que ignora por completo la dimensión ética de la experiencia humana (Bolton, 2014, p. 4). Es la complicidad humana con la integración de la otredad tecnológica la que nos transforma en nuestro propio enemigo, pues lo humano se perdería en la interfaz. Los ejemplos en la literatura y el cine de mundos distópicos en los que la biología de la maternidad ha sido reemplazada e industrializada se tienden a organizar a partir de: 1) el deseo de dominar y serializar los procesos reproductivos: Un mundo feliz (Huxley, 1932), Matrix (Wachowski, 1999), Gattaca (Niccol, 1997); y 2) la infertilidad de un mundo que ha agotado su reserva biológica producto de la desigualdad, la guerra y el extractivismo: Children of Men (Cuarón, 2006), I mother (Sputore, 2019), El cuento de la criada (Atwood, 1985).

En "Conservas" una mujer joven, emparejada, que aún estudia, queda embarazada y junto a su pareja decide que no es el momento para la maternidad. El deseo de ser madre existe, por lo que la protagonista encuentra un médico alternativo que le ofrece un método para revertir la gestación de forma fisiológica y psicológica sin tener que abortar. El proceso transformará al embrión en una semilla humana del tamaño de una almendra que la protagonista luego expulsará por la boca y guardará en un frasco de con- 
servación. El método se presenta como científico en términos de resultados observables, pero la forma en que se lleva a cabo el proceso se expresa por medio de un lenguaje característico del new age o el mindfulness. Así, técnicas como la "respiración consciente", cambios de alimentación y sueño y la cooperación de familiares son fundamentales para revertir la gravidez. El proceso se representa como el anverso de un tratamiento de fertilidad y su lenguaje motivacional es también el del mercado reproductivo. El cuerpo de la madre, en su calidad de productor de vida, es doblegado a voluntad para revertir un embarazo que termina en la expulsión de una semilla humana que se guarda en un frasco. El cuento cierra con la escena perturbadora de un parto a la inversa: "Es una sensación inconfundible que guardaré hasta dentro de algunos años (...) ella estará bien hasta el momento indicado: entonces Manuel me acerca el vaso de conservación, y al fin suavemente la escupo" (p. 33). La detención del tiempo es un motivo literario asociado a la muerte o el entierro vivo del gótico y el parto que ocurre desde la cabeza (la boca) que, además, es racionalizado y encapsulado como vida en potencia, se inscriben en una tradición de criaturas que son creadas entre la vida y la muerte, y que, como Frankenstein, se originan en un ejercicio de dominio.

"En la estepa", de la misma autora, representa dentro de los parámetros del presente un mundo distópico en el cual se deduce que los humanos asentados o civilizados han perdido su capacidad de concebir hijos, pues, únicamente nacen en estado salvaje en la estepa semi-desértica. Pol, el marido de Ana, la narradora, conoce a Arnol y Nabel, una pareja que, a diferencia de ellos, ya atrapó un hijo y acepta una invitación a cenar. Mientras anticipan el evento de la noche, Ana cuenta que cuando salen de cacería nocturna su marido es el que se preocupa de la escopeta, en tanto que ella se concentra en tener pensamientos fértiles, un consejo que ha aprendido de las revistas para mujeres. La narradora evidencia la forma en que el pensamiento mágico, decantado en recomendaciones para la fertilidad, amplifica en su narcisismo la violencia de las cacerías nocturnas.

La pareja que visitan vive a unos kilómetros de su estancia y en el camino Ana piensa en las cosas que desea preguntarle a Nabel y espera que se genere la complicidad necesaria para esto. Durante la cena los anfitriones hacen lo posible por aplazar el develamiento de la criatura (casi nunca llamada hijo) con distintos pretextos, sin embargo, bajo la excusa de usar el baño, Pol se escabulle a la habitación del ser que atraparon y luego de un fuerte golpe grita horrorizado. La escena es confusa y violenta, pues después de escuchar que cosas se rompen, el anfitrión toma la escopeta y la pareja protagonista huye despavorida. Mientras aceleran en la ruta camino 
a casa, la protagonista teme que con la velocidad puedan atropellar a un animal o a "uno de ellos", quizás el suyo. El cuento cierra la colección con una imagen de horror no resuelta, otro entierro vivo de niños atrapados y deseo maternal frustrado. La pareja no puede hablar sobre el horror que acaban de vivir, ya que la maternidad y su deseo se ha codificado en un lenguaje de revista femenina, antes reservado para el amor romántico, que no tiene palabras para referirse a la violencia asociada al deseo de dominio inherente a la persecución de la maternidad en un mundo estéril.

Un joven sentado frente a una pantalla en su dormitorio es la imagen principal del cuento "Verde rojo anaranjado" de Mariana Enriquez, y esta es una escena que como sujetos contemporáneos reconocemos con facilidad. El temor a que un hijo, un amigo o uno mismo sea devorado por una máquina tan cotidiana como la computadora, se representa en este cuento mediante la figura de Marco, un joven que gradualmente comienza a encerrarse en su habitación y a comunicarse vía Messenger (la plataforma de chat que los jóvenes utilizaban en el cambio de siglo). La madre pierde el vínculo con su hijo, pues este ha reemplazado las interacciones reales y materiales por las virtuales. La narradora explica el comportamiento de Marco diciendo que "la gente triste no tiene piedad" (p. 176), sin embargo, mediante este comentario, también da cuenta de la forma en que la fusión con la máquina ha ido eliminando su capacidad de empatía.

La impotencia y el dolor asociado a la rotura del vínculo empuja también a la madre a ausentarse en un "sueño químico" (p. 184) producido por drogas psicotrópicas, diseñadas para encender y apagar distintas funciones (así como los estados de rojo, verde y amarillo de Messenger). Madre e hijo se desvanecen respectivamente en sus mundos artificiales y progresivamente comienzan a vivir en la esfera de lo espectral. En el caso de Marco, acechado por los fantasmas japoneses de un tal cuarto rojo de la deep web y en el caso de la madre, acompañada por la calidad fantasmal y parásita de un hijo para el cual cocina, pero que nunca ve. La única capaz de comunicarse con Marco es la narradora del cuento, quien en su condición de ex amante y por chat retiene por un tiempo la atención del joven:

Si fueras una máquina no me dirías eso.

No, escribe. Pero ¿cómo te vas a dar cuenta cuando sí sea una máquina? No me voy a dar cuenta, le contesto. Ese robot no existe todavía, sacaste la idea de una película.

Es una idea hermosa, escribe. (pp.183-184) 
El síndrome de Hikikomori, descrito como un aislamiento producto de la inhabilidad de lidiar con las presiones del mundo exterior, se representa en este cuento como un hijo que cruza el umbral hacia otro mundo desde una pantalla (igual a la que tenemos todos) en un dormitorio y se convierte en fantasma. Si seguimos la premisa narcisista de King, podríamos leer la desaparición del hijo en este cuento como una expresión agorafóbica de un joven que encuentra dentro de las cuatro paredes de su dormitorio el espejo digital que le permite seguir sus obsesiones hasta consumirse o enterrarse vivo en ellas.

\section{CONCLUSIONES}

María Negroni plantea que el gótico no solo desestabiliza y expande la noción que se tiene de la realidad, sino que en la línea de Kosofsky, da cuenta de las dimensiones no controlables o difíciles de articular de la experiencia. El gótico advierte sobre aquello que "está todo el tiempo tensando desde abajo" (Boullosa, 2010, párr. 4), enterrado vivo como Lady Madeline, hermana de Roderick Usher (juntos, los últimos descendientes incestuosos de "La caída de la casa de Usher" de Edgar Allan Poe ([1839] 2007)) cuyos golpes desesperados escuchamos de noche a pesar de los esfuerzos de nuestra razón por atribuírselos a la tormenta. Negroni agrega que aquello que late debajo de nuestras representaciones de la realidad tiene que ver con lo femenino, es decir, con aquella parte de la experiencia obliterada por la cultura patriarcal que, en el caso de los textos discutidos acá, da cuenta de la complejidad de las labores de cuidado y los miedos que estas suscitan. Los motivos de la casa acechada y la intervención tecnológica en la reproducción y el cuidado de la vida posibilitan por medio del horror la representación en la narrativa de Enriquez y de Schweblin de una madre que independientemente de su presencia o ausencia se configura como la miembro de la familia y la sociedad capaz de hacer más daño. Si bien la madre funciona como chivo expiatorio de una cultura paranoica que encierra sus complejidades y el miedo a su omnipresencia dentro de la figura ideológica de la maternidad burguesa y entierra el resto al obliterar la fuerza de su experiencia y potencial, el horror en los cuentos analizados emerge de la imposibilidad de la mujer de proteger la vida nueva de los espantos de nuestro mundo. La figura de la madre en la que coinciden los cuentos de Schweblin y Enriquez fracasa debido a que es tanto víctima como cómplice 
de la monstruosidad de la descendencia. La historia de horror que cuentan estos relatos es la de una mujer que debido a su impotencia y vulnerabilidad alimenta, junto a la vida que no puede proteger, a un monstruo mayor, voraz y antiguo que se actualiza en la Argentina neoliberal del cambio de siglo.

\section{REFERENCIAS}

Amenábar, A. (dir.), Bovaira. F., \& Cyerda, J.L. Park, S. (productores). (2001). The Others (Película). España: Las producciones del Escorpión y Sociedad General de Cine, S.A.

Aronofsky, Darren (dir.) \& Franklin, S. y Handel, A. (productores). (2017). Mother! (Película). EEUU: Protozoa Pictures.

Atwood, M. ([1985] 2017). El cuento de la criada. (Trad. de Elsa Mateo Blanco). Barcelona: Salamandra.

Bolton, M. S. (2014). Monstrous Machinery: Defining Posthuman Gothic. Aeternum: The Journal of Contemporary Gothic Studies 1(1), 1-15.

Bombal, M.L. ([1931/1946] 2004). La última niebla. La historia de María Griselda. La última niebla/ La Amortajada (pp. 9-44). Barcelona: Seix Barral.

Boullosa, C. (8 de enero, 2010). María Negroni. "En la literatura fantástica, lo femenino es casi lo único que importa”. Ñ Revista de Cultura. Recuperado de https://web.archive.org/web/20120102035143/http://edant.revistaenie. clarin.com/notas/2010/01/08/_-02115427.htm

Butler, J. (2009). Frames of War. New York: Verso.

Cavallaro, D. (2002). The Gothic Vision: Three Centuries of Horror, Terror, and Fear. New York: Continuum.

Cohen, J. (1996). Monster culture (Seven Thesis). En J. J. Cohen (ed). Monster Theory: Reading Culture (pp. 1- 25). Minneapolis: University of Minneapolis Press.

Cortázar, J. (1975). Notas sobre lo gótico en el Río de la Plata. Cahiers du monde hispanique et luso-brésilien 25, 145-151.

Cortázar, J. ([1946] 2002). Casa tomada. Cuentos completos/1 (pp. 107-111). Ciudad de México: Alfaguara.

Cortázar, J. ([1956] 2011). Los venenos, Final del juego. Final del juego (pp. 3152, 235-252). Buenos Aires: Alfaguara.

Cuarón, A. (dir.) \& Shor, H., Smith, I. Smith, T., Abraham, M. y Newman, E. (productores). (2006). Children of Men (Película). EE.UU. y R.U.: Hit and Run Productions y Strike Entertainment.

Darío, R. (1896). Los raros. Buenos Aires: La Vasconia.

Darío, R. ([1925]1995). Thanatopía. Verónica y otros cuentos fantásticos (pp. 8-14). Madrid: Alianza.

Donoso, J. ([1957] 2005). Coronación. Santiago: Alfaguara. 
Donoso, J. ([1970] 2016). El obsceno pájaro de la noche. Santiago: Alfaguara.

Enriquez, M. (2016). Las cosas que perdimos en el fuego. Barcelona: Anagrama. Freud, S. ([1919] 2003). The Uncanny. (Trad. de David Mclintock). London: Penguin Books.

Gilbert, S. \& Gubar, S. (1979). The Mad Woman in the Attic: The Woman Writer and the Nineteenth- Century Literary Imagination. New Haven: Yale University Press.

Gorriti, J. M. ([1865] 2018) Sueños y realidades. Obras completas de Juana Manuela Gorriti. Sydney: Wentorth Press.

Heise-von der Lippe, A. (ed). (2017). Posthuman Gothic. Cardiff: University of Wales Press.

Horkheimer, M. \& Adorno, Th. (2002). Dialectic of the Enlightenment: Philosophical Fragments. (Trad. de Edmund Jephcott). Stanford: Stanfrord University Press.

Huxley, A. ([1932] 1985). Un mundo feliz. Ciudad de México: Editores Mexicanos Unidos.

Lugones, L. (1906). Los caballos de Abdera. Las fuerzas extrañas (pp. 123-136). Buenos Aires: Arnolodo Moen y Hermano Editores.

Kent, J. (dir.) \& Ceyton, K y Moliere, K. (productores). (2014). The Babadook (Película). Australia: Screen Australia y Causeway Films.

King, S. (1987). Dance Macabre. New York: Berkley Books.

Kosofsky, E. (1980). The Coherence of Gothic Conventions. New York: Methuen. Kristeva, J. (1988). Poderes del horror. (Trad. de Nicolás Rosa). Madrid: Siglo XXI.

Niccol, A. (dir.) \& DeVito, D., Shamberg, M. y Sher, S. (productores). (1997). Gattaca (Película). EE.UU: Columbia Pictures.

O'Connor, F. (1970). Some Aspects of the Grotesque in Southern Literature. En F. O'Connor, S. Fitzgerald, \& R. Fitzgerald (eds). Flannery O'Connor: Mysteries and Manners (pp. 38-50). New York: Farrar, Strauss \& Giroux.

Ocampo, S. ([1937] 1999). Cielo de claraboyas. Silvina Ocampo: Obras completas (pp. 5-6). Buenos Aires: Emecé Editores.

Ocampo, S. ([1959] 2006). El vestido de terciopelo. La furia (pp. 155-160). Buenos Aires: Editorial Sudamericana.

Olmedo, N. (2013). Ecos góticos en la novela del Cono Sur. Newark: Estudios de la Literatura Latinoamericana-Juan de la Cuesta.

Poe, E. A. ([1839] 2007). La caída de la Casa Usher. Cuentos, 1 (pp. 317-337). (Trad. de Julio Cortázar). Buenos Aires: Alianza Editorial.

Polansky, R. (dir.) \& Castle, W. (productor). (1968) Rosemary's Baby (Película). EE.UU: William Castle Enterprises.

Punter, D. (1999). Introduction. En G. Byron \& D. Punter (eds.). Spectral Readings: Towards a Gothic Geography (pp. 1-8). Londres: MacMillan Press.

Quiroga, H. ([1910] 1994). El hombre artificial. Novelas completas (pp. 105129). Buenos Aires: Ediciones Rafael Cedeño.

Schweblin, S. (2015a). Siete casas vacías. Madrid: Páginas de espuma.

Schweblin, S. (2015b). Pájaros en la boca. Buenos Aires: Random House. 
Shelley, M. (2013). Frankenstein; or, the Modern Prometheus. London: Penguin Books.

Sputore, G. (dir.) \& Murno, K. Y White, T. (productores). (2019) I mother (Película). Australia y EE.UU.: Penguin Empire, Southern Lights Film, Mister Smith Entertainment y Endeavor Content.

Tatar, M. (1981). The Houses of Fiction: Toward a Definition of the Uncanny, Comparative Literature 33(2), 167-182.

Wachowski, L. y Wachowski, L. (dir.), Silver, J. (productor). (1999). Matrix. (Película). EE.UU: Warner Bros.

Walpole, H. ([1764] 2016). El castillo de Otranto. (Trad. de Gloria Susana Esquivel). Bogotá: Idartes. 